\title{
A human face carved on a pebble from the Late Natufian site of Nahal Ein Gev II
}

\author{
Leore Grosman ${ }^{1,2, *}$, Dana Shaham ${ }^{1}$, Francesco Valletta ${ }^{1}$, Itay Abadi ${ }^{1}$, \\ Hadas Goldgeier ${ }^{1}$, Noa Klein ${ }^{1}$, Laure Dubreuil ${ }^{3} \&$ Natalie D. Munro ${ }^{4}$
}

There is a paucity of Palaeolithic art in the southern Levant prior to 15000 years ago. The Natufian culture (15000-11 500 BP; Grosman 2013) marks a threshold in the magnitude and diversity of artistic manifestations (Bar-Yosef 1997). Nevertheless, depictions of the human form remain rare-only a few representations of the human face have been reported to date. This article presents a 12000 -year-old example unearthed at the Late Natufian site of Nahal Ein Gev II (NEGII), just east of the Sea of Galilee, Israel (Figure 1). The object provides a glimpse into Natufian conventions of human representation, and opens a rare opportunity for deeper understanding of the Natufian symbolic system.

\section{The human face carved on a pebble and its parallels}

The NEGII face is carved from a limestone pebble measuring $90 \times 60 \mathrm{~mm}$. Minimalistic manipulation of the pebble's surface creates a simple but realistic human expression. The artist used the natural form of the pebble to represent the outline of a human head, and slightly modified the stone's perimeter with a flat band to shape the contours of the face (Figure 2a). The main modification engraved on the front of the pebble consists of a Tshaped linear relief that emphasises an eyebrow ridge and nose; two low arcs that meet at the centre of the pebble form the eyebrow ridge and then turn downward to depict a straight, elongated nose.

By skilful play with line depth and curvature, the artist has achieved a soft depiction of the cheeks and deep, shaded eye sockets (Figure 3). The artistic qualities of the representation are schematic, but they present a realistic and uniquely expressive human face. The back of the pebble is not carved but is lightly modified at the edges. Microscopic analysis shows a few small, smooth and shiny areas that may have been created by gentle polishing of the surface with a soft material such as skin or fabric, or by contact with soft fabric wrappings

\footnotetext{
Institute of Archaeology, The Hebrew University, Mount Scopus, Jerusalem 91905, Israel

The Jack, Joseph and Morton Scholion-Mandel School for Advanced Studies in the Humanities, The Hebrew University of Jerusalem, Israel

3 Anthropology Department, Trent University, 1600 West Bank Drive, Peterborough, ON, K9L OG2, Canada

4 Department of Anthropology, University of Connecticut, Unit 1176, 354 Mansfield Road, Storrs, CT 062691176, USA

* Author for correspondence (Email: leore.grosman@mail.huji.ac.il)
}

(C) Antiquity Publications Ltd, 2017 ANTIQUITY 91 358, e2 (2017): 1-5 


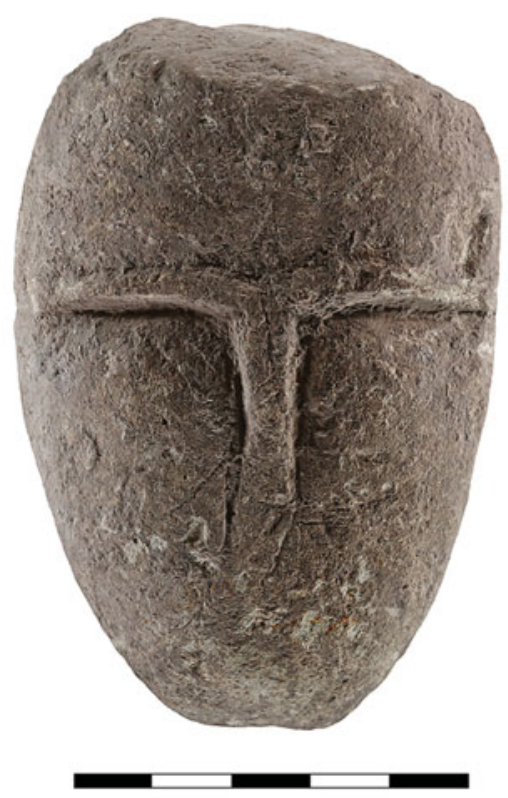

Figure 1. The human face carved on a limestone pebble from Nahal Ein Gev II (Late Natufian) (photograph by Gabi Laron).

a.

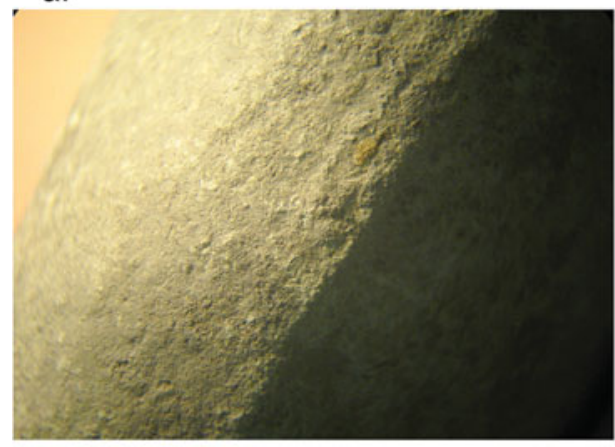

b.
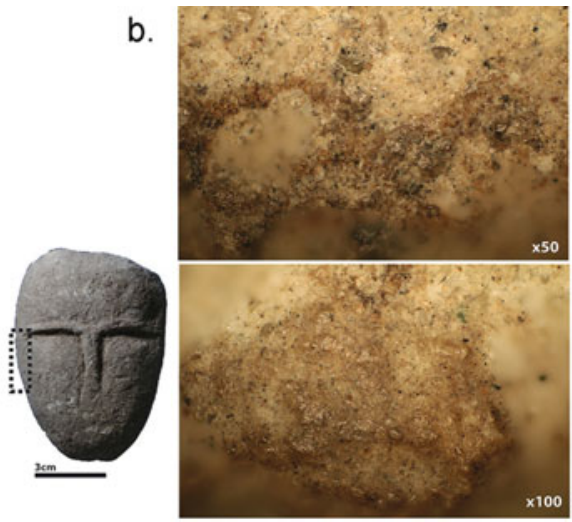

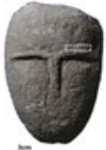

Figure 2. a) The flattened band around the edge of the pebble; $b$, top) stereomicroscope observation at $6 \times$ magnification; $b$, bottom) micropolish associated with the dark and shiny areas observed at high magnification. The micropolish is discontinuous, bright and smooth (the magnified area is marked by the rectangle).

(Dubreuil 2004; Dubreuil et al. 2015; Figure 2b). No residues or signs of colouration adhere to the stone's surface.

A small yet diverse group of anthropomorphic human representations have been recovered from Natufian contexts (e.g. Perrot 1966: figs 21.17 \& 23.1; Weinstein-Evron 1998: fig. 58.2-3). To date, only three pebbles depict the human face: one from el-Wad Cave (Garrod \& Bate 1937: pl. XIII.4) and two from Eynan (Perrot 1966: fig. 23.2-3) (Figure 4).

(C) Antiquity Publications Ltd, 2017 

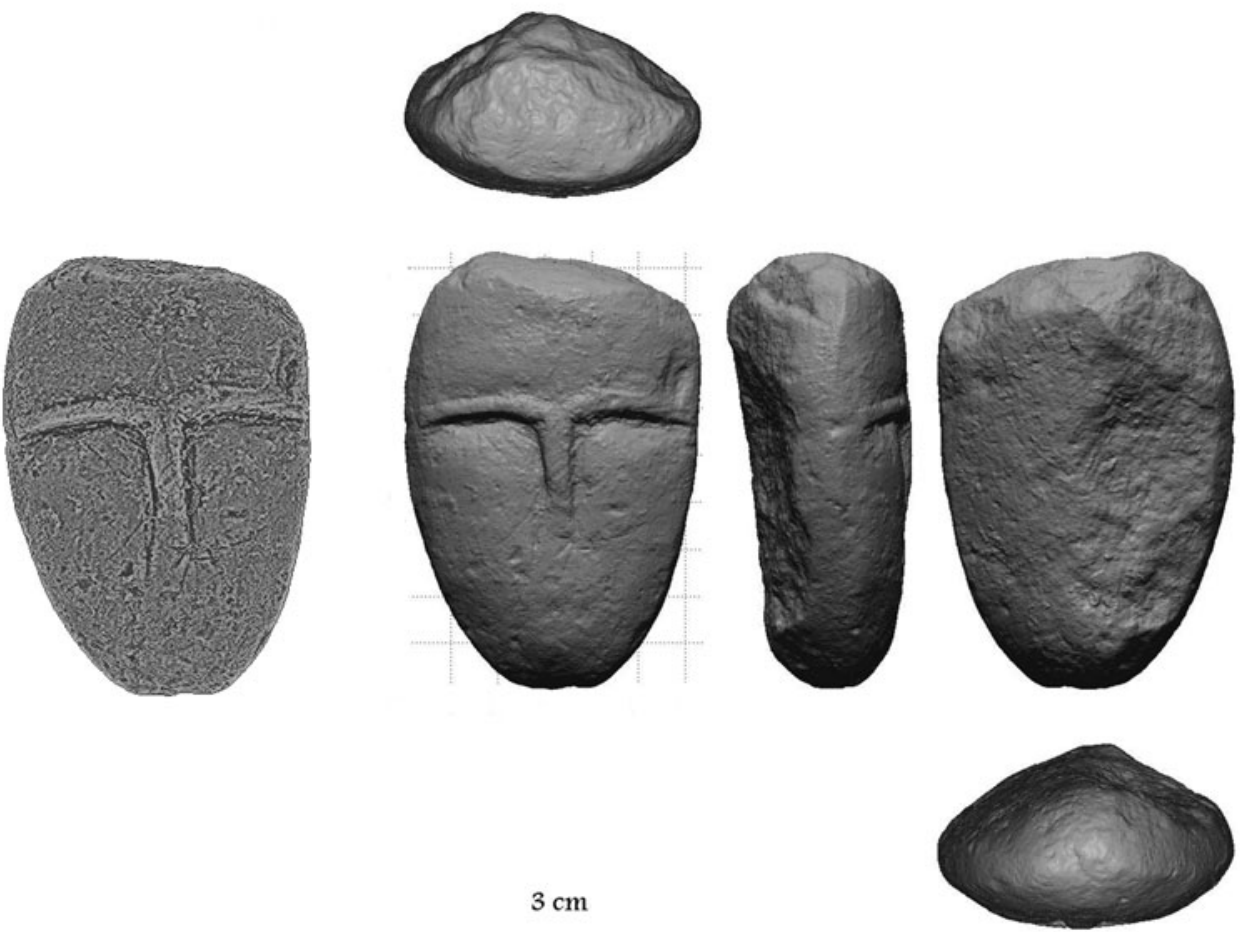

Figure 3. 3D scan of the Nahal Ein Gev II stone face documented in Artifact3-D (Computerized Archaeology Laboratory, Institute of Archaeology, The Hebrew University; Grosman et al. 2014). The grey rendering provides a clear visualisation of the geometry of the object, specifically the lines that depict the face. Note the carved lines that deviate from the lower part of the nose to the left.

a

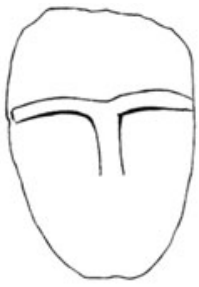

C

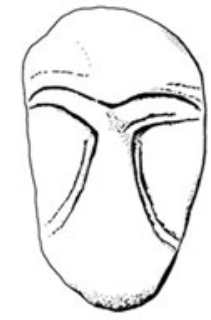

b

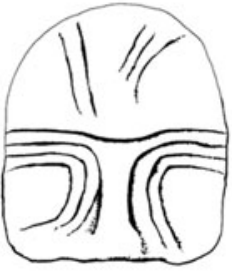

d

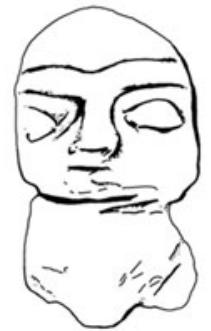

Figure 4. Comparison of human faces on pebbles: a) Nahal Ein Gev II; b-c) Eynan (after Perrot 1966); and d) el-Wad (after Garrod \& Bates 1937) (not to scale, drawn by Hadas Goldgeier). 


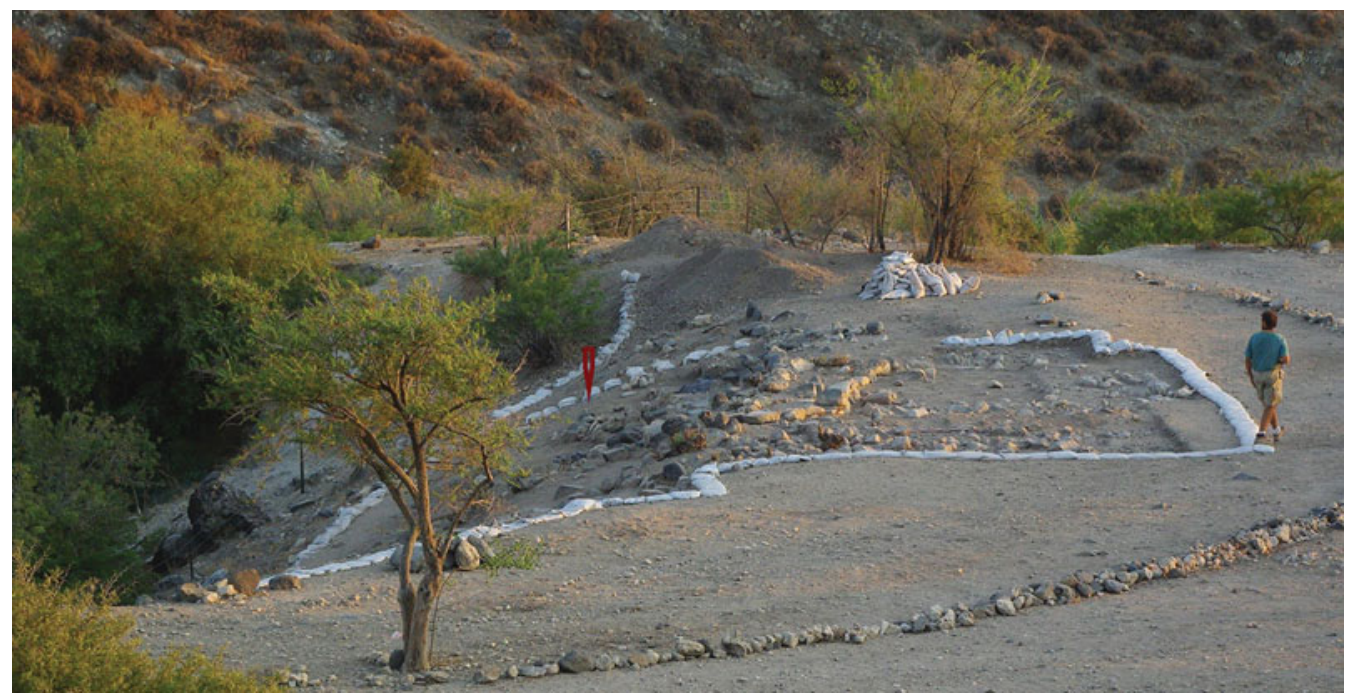

Figure 5. Area B at Nahal Ein Gev II in 2016, a view to the south-east. The location of the findspot is indicated by the red arrow (photograph by Dana Shaham).

Collectively, these stone faces share an artistic quality-the eyebrow ridge and nose are drawn in linear relief, resulting in a schematic depiction. The stone face from NEGII is most similar to one of the two examples from Eynan (Figure 4c); both are minimalisticthe image is created by only a few lines. Yet the stone face from NEGII is unique in its more precise representation of human expression.

\section{Nahal Ein Gev II}

The NEGII site is located on a flat alluvial terrace on the right bank of Nahal (wadi) Ein Gev. The site dates to the very end of the Natufian period (12 550-12 000 cal BP). Abundant architecture, built features and thick archaeological deposits suggest that it represents a large, intensive village that was inhabited for several centuries (Grosman et al. 2016).

The excavations and test pits at NEGII reveal an extensive habitation area covering around $1200 \mathrm{~m}^{2}$. Excavations have concentrated on the naturally sloping eastern edge of the site, which was partially eroded by a stream. The deep stratigraphy $(2.5-3 \mathrm{~m}$ deep) contains only a homogeneous Natufian unit that can be divided into multiple construction sub-phases. Dense material remains, particularly lithic artefacts, are distributed throughout the layers. Lithic attributes verify the chronological assignment of the site to the end of the Late Natufian.

On the first day of the 2016 excavation season, a path was constructed down the eroded east slope of the site to contain foot traffic and to protect the loose, sloping, Natufian deposits. During construction, the carved-stone human face was discovered on the surface of the exposed Natufian deposits (Figure 5), in excavation square RG63. Although we are certain that it was embedded in Late Natufian deposits, the square remains unexcavated, and thus we do not yet know its specific archaeological context (e.g. structure or feature).

(C) Antiquity Publications Ltd, 2017 


\section{Discussion}

The human face carved on a pebble from NEGII shows a schematic depiction that lacks detail. This quality also characterises other Natufian human-face representations, and thus might reflect a Natufian cultural convention. Schematisations of this kind generalise the human face rather than offering an individual 'portrait'. Nevertheless, unlike other Natufian carved-pebble faces, the cheeks of the example from NEGII are softly moulded, while the eye sockets are emphasised using expressive shading: qualities that create a lively expression.

The three other carved-stone human faces are Early Natufian in date, whereas NEGII is dated to the end of the Late Natufian. Consequently, the NEGII example may reflect either a virtuosic artist or part of a diachronic trend that bridges the Early Natufian and Early Neolithic artistic traditions. Other aspects of the NEGII art assemblage (Grosman et al. 2016) exhibit a style that is closely related to the Early Neolithic world, although it reveals deep roots in the Early Natufian tradition. Importantly, these changes in art accompany other documented changes in subsistence, settlement and technology that are already underway by the very end of the Natufian period.

\section{Acknowledgements}

We thank the students of the Institute of Archaeology, The Hebrew University and other Israeli and international institutions for participating in fieldwork at NEGII. Special thanks go to Keren Nebenhous, who found the object. This research was supported by the Israel Science Foundation (1415/14 to L.G.) and the National Science Foundation (BCS-1318381 to N.D.M.); Israel Antiquities Authority permit G-77/2016 (L.G.); Nature Parks Authority permit to excavate at Ein-Gev 24/16 N (L.G.).

\section{References}

Bar-Yosef, O. 1997. Symbolic expressions in later prehistory of the Levant: why are they so few?, in M. Conkey, O. Soffer, D. Stratmann \& N.G. Jablonski (ed.) Beyond art: Pleistocene image and symbol (Memoirs of the California Academy of Sciences 23). San Francisco: California Academy of Sciences.

Dubreuil, L. 2004. Long-term trends in Natufian subsistence: a use-wear analysis of ground stone tools. Journal of Archaeological Science 31: 1613-29. https://doi.org/10.1016/j.jas.2004.04.003

Dubreuil, L., D. Savage, S. Delgado, I. de la Torre, H. Plisson \& B. Stephenson. 2015. Use-wear analysis of ground stone tools: discussing our current framework, in J. Marreiros, J. Gibaja \& $\mathrm{N}$. Bicho (ed.) Use-wear and residue analysis in archaeology. Cham: Springer.

Garrod, D.A.E. \& D.M.A. Bate. 1937. The Stone Age of Mount Carmel. Oxford: Clarendon.
Grosman, L. 2013. The Natufian chronology scheme-new insights and their implications, in O. Bar-Yosef \& F.R. Valla (ed.) Natufian foragers in the Levant. Ann Arbor (MI): International Monographs in Prehistory.

Grosman, L., A. Karasik, O. Harush \& U. SMILANSKy. 2014. Archaeology in three dimensions-computer-based methods in archaeological research. Journal of Eastern Mediterranean Archaeology and Heritage Studies 2: 48-64.

https://doi.org/10.5325/jeasmedarcherstu.2.1.0048

Grosman, L., N.D. Munro, I. Abadi, E. Boaretto, D. Shaham, A. Belfer-Cohen \& O. Bar-Yosef. 2016. Nahal Ein Gev II, a Late Natufian community at the Sea of Galilee. PLoS ONE 11: e0146647. https://doi.org/10.1371/journal.pone.0146647

Perrot, J. 1966. Le gisement Natoufien de Mallaha (Eynan), Israël. L'Anthropologie 70: 437-84.

Weinstein-Evron, M. 1998. Early Natufian el-Wad revisited. Liège: Université de Liège. 